\title{
Spatial and temporal effects of climate change and land use change on runoff, sediment, nitrogen and phosphorus loss in the Haihe River Basin over the past 40 years
}

\author{
nan ding ${ }^{1}$, yi chen ${ }^{1}$, and Fulu Tao ${ }^{2}$ \\ ${ }^{1}$ Institute of Geographic Sciences and Natural Resources Research CAS \\ ${ }^{2}$ Institute of Geographic Sciences and Natural Resources Research Chinese Academy of \\ Sciences
}

September 24, 2021

\begin{abstract}
Investigating the impacts of climate and land use changes on basin's hydrological cycle and environment is important to provide scientific evidence to manage the trade-off and synergies among water resource, agricultural production and environment protection. In this study, we quantified the contributions of climate and land-use changes to runoff, sediment, nitrogen and phosphorus losses in the Haihe River basin since the 1980s. The results showed that (1) climate and land-use changes significantly increased evapotranspiration (ET), transport loss (TL), sediment input (SI) and output (SO), and organic nitrogen (ON) and phosphorus production (OP), with ET, SI, and ON affected most. (2) The runoff, sediment and ammonia nitrogen were affected most by climate and land use changes in the Daqing River Basin (217.3 mm), Nanyun River Basin (3917.3 ton) and Chaobai River Basin $(87.6 \mathrm{~kg} / \mathrm{ha})$, respectively. (3) The impacts of climate and land-use changes had explicit spatial-temporal patterns. In the Daqing River, Yongding River and Nanyun River, the contribution of climate change to runoff and sediment kept increasing and reached $88.6 \% \sim 98.2 \%$ and $63 \% \sim 77.2 \%$, respectively. In the Ziya River and Chaobai River Basin, the contribution of land use was larger, reaching $88.6 \%^{\sim} 92.8 \%$ and $59.8 \%^{\sim} 92.7 \%$, respectively. In the Yongding River Basin, Chaobai River Basin, Ziya River Basin and Daqing River Basin, the contribution of land use to nitrogen and phosphorus loss showed an increasing trend in the past 40 years (maximum: 89.7\%). By contrast, in Nanyun River and Luanhe River, the contribution of climate change to nitrogen and phosphorus loss increased more obviously (maximum: 92.1\%). We quantitatively evaluated the spatial and temporal impacts of climate and land-use changes on runoff, sediment, and nitrogen and phosphorus loss, which are useful to support the optimizations of land and water resources in the River Basin.
\end{abstract}

\section{Hosted file}

MS20210811.docx available at https://authorea.com/users/435616/articles/538511-spatial-andtemporal-effects-of-climate-change-and-land-use-change-on-runoff-sediment-nitrogen-andphosphorus-loss-in-the-haihe-river-basin-over-the-past-40-years

\section{Hosted file}

table.docx available at https://authorea.com/users/435616/articles/538511-spatial-andtemporal-effects-of-climate-change-and-land-use-change-on-runoff-sediment-nitrogen-andphosphorus-loss-in-the-haihe-river-basin-over-the-past-40-years 

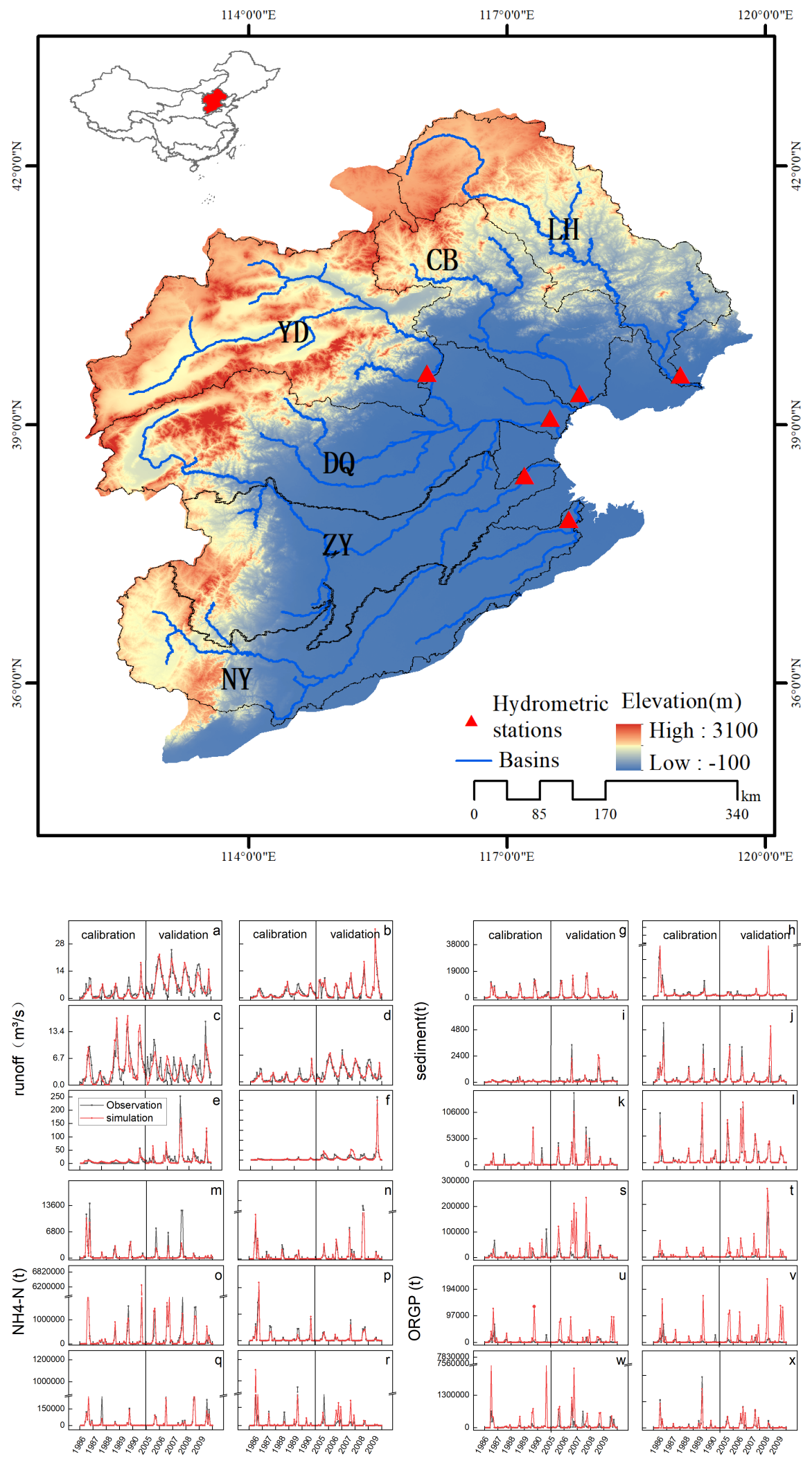

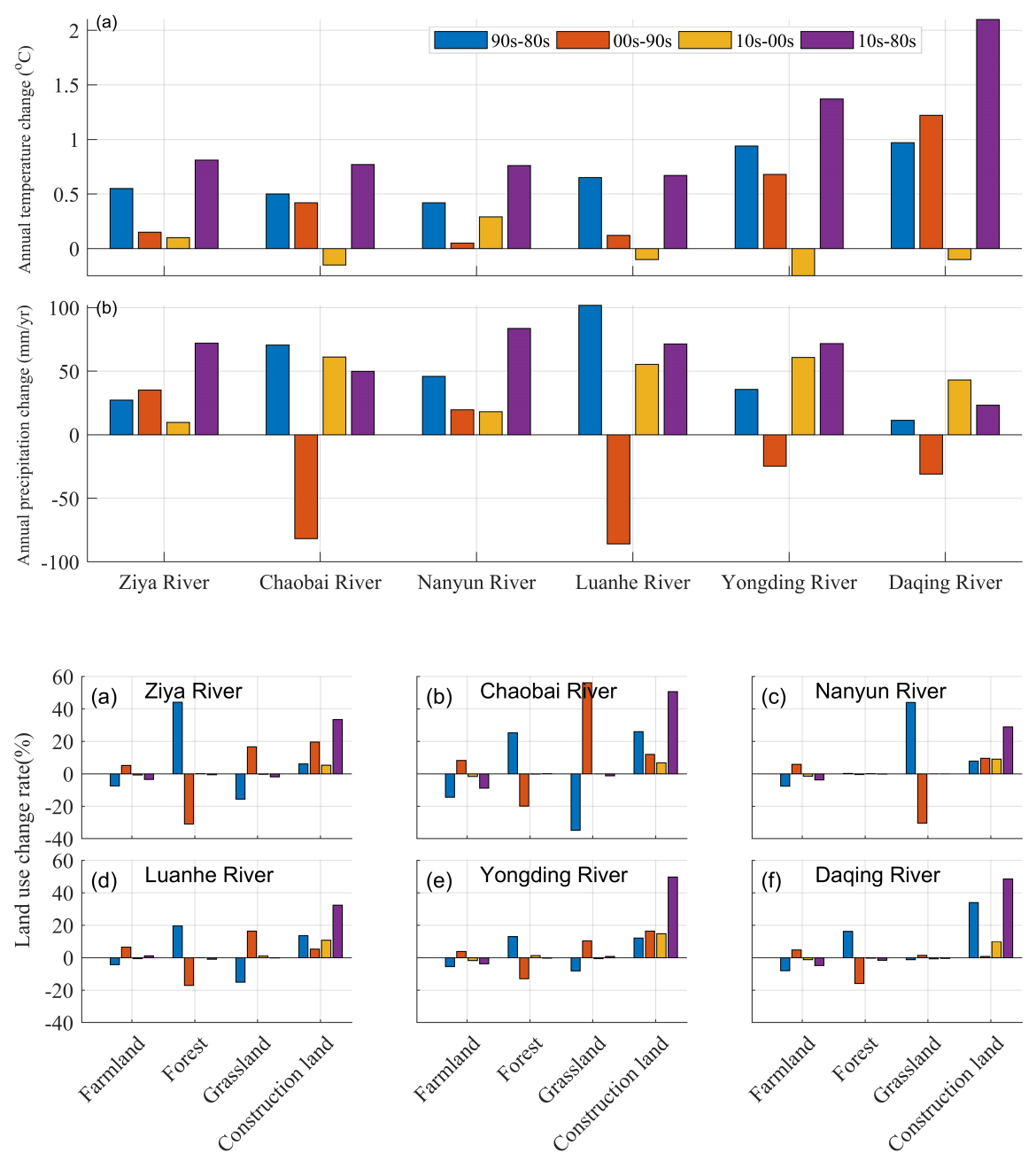

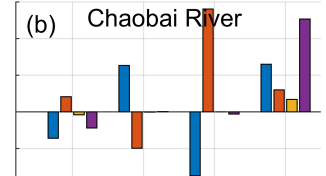

(e) Yongding River

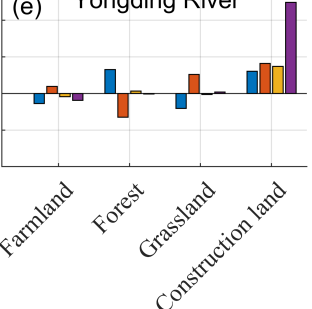

(c) Nanyun River

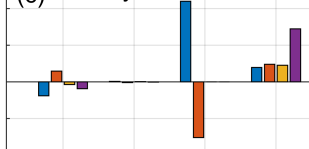

(f) Daqing River
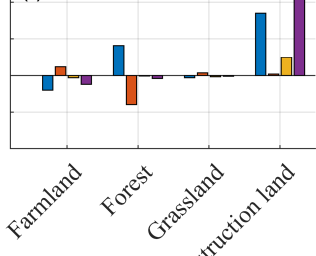

1995 2005 $\square 2005 \sim 2015$

$1985 \sim 2015$ 

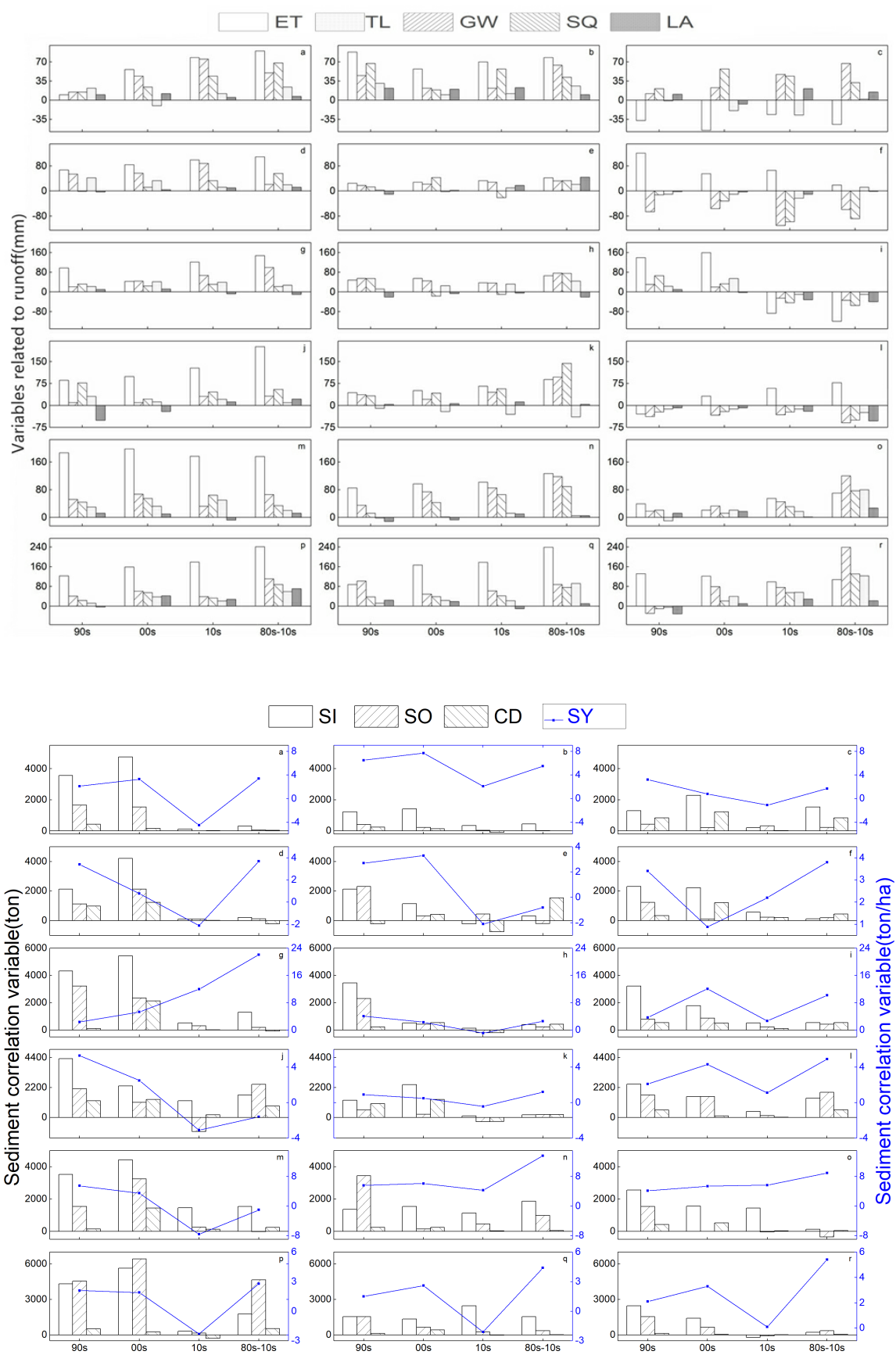

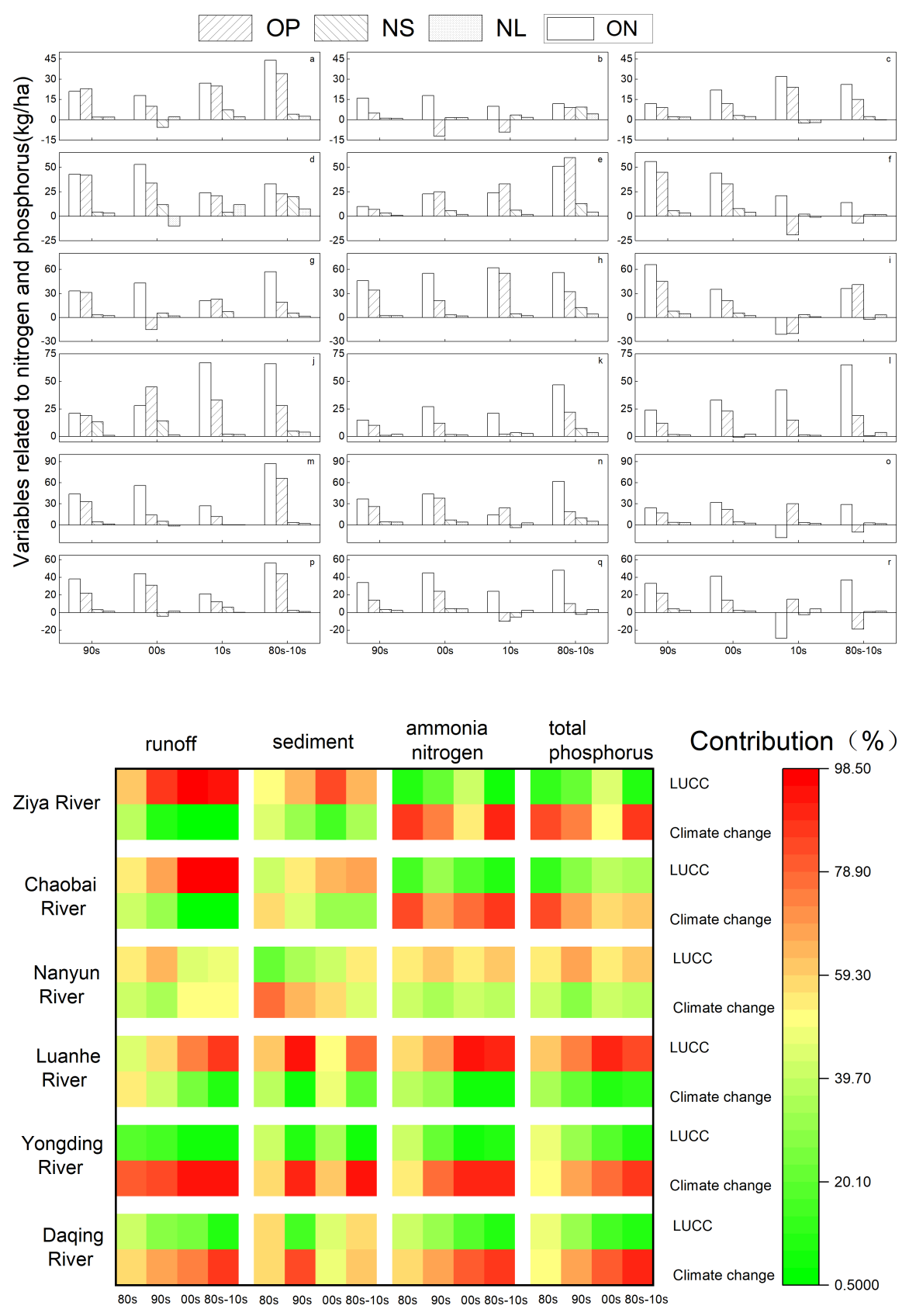